\title{
Intumescent flame retardant polyurethane/reduced graphene oxide composites with improved mechanical, thermal, and barrier properties
}

\author{
Jaber Nasrollah Gavgani - Hossein Adelnia • \\ Mohsen Moazzami Gudarzi
}

Received: 27 July 2013/ Accepted: 23 August 2013/Published online: 11 September 2013

(C) Springer Science+Business Media New York 2013

\begin{abstract}
Intumescent flame retardant polyurethane (IFRPU) composites were prepared in the presence of reduced graphene oxide (rGO) as synergism, melamine, and microencapsulated ammonium polyphosphate. The composites were examined in terms of thermal stability (both under nitrogen and air), electrical conductivity, gas barrier, flammability, mechanical, and rheological properties. Wide-angle X-ray scattering and scanning electron microscopy indicated that $\mathrm{rGO}$ are well-dispersed and exfoliated in the IFRPU composites. The limiting oxygen index values increased from 22.0 to 34.0 with the addition of $18 \mathrm{wt} \%$ IFR along with $2 \mathrm{wt} \%$ rGO. Moreover, the incorporation of rGO into IFRPU composites exhibited excellent antidripping properties as well as UL-94 V0 rating. The thermal stability of the composites enhanced. This was attributed to high surface area and good dispersion of rGO sheets induced by strong interactions between $\mathrm{PU}$ and rGO. The oxygen permeability, electrical, and viscoelasticity measurements, respectively, demonstrated
\end{abstract}

J. N. Gavgani · H. Adelnia

Department of Polymer Engineering and Color Technology,

Amirkabir University of Technology, P.O. Box 15875-4413,

Tehran, Iran

J. N. Gavgani

Department of Chemical Engineering, Amirkabir University

of Technology, P.O. Box 15875-4413, Tehran, Iran

\section{H. Adelnia}

Department of Polymer Engineering, Islamic Azad University-

Shahreza Branch, P.O. Box: 86145-311, Shahreza, Iran

M. M. Gudarzi ( $\square)$

Department of Inorganic and Analytical Chemistry, School of Chemistry and Biochemistry, University of Geneva, Geneva, Switzerland

e-mail: mohsen.moazzami@unige.ch that rGO lead to much more reduction in the gas permeability (by $\sim 90 \%$ ), high electrical conductivity, and higher storage modulus of IFRPU composites. The tensile strength, modulus, and shore A remarkably improved by the incorporation of $2.0 \mathrm{wt} \%$ of $\mathrm{rGO}$ as well.

\section{Introduction}

Polyurethanes (PU) are an important class of thermosets for a variety of applications such as coating, foaming, adhesives, sealants, biomimetic materials, and synthetic leathers due to their useful properties such as excellent flexibility, elasticity, and damping ability [1]. Though PU possess good deformability, their high flammability, low stiffness, and tensile strength limit their use in numerous structural applications [2].

In recent years, the demand for flame retardant has substantially altered and environmental protection and legislation have become key factors in selection of flame retardant. Since halogenated flame retardant(s) release ambiguous, corrosive, and toxic smoke while performing fire retardant action [3-5], the focus has recently been on extending halogen-free flame retardants, especially intumescent flame retardant (IFR). However, high loading of IFR (in some cases, more than $30 \mathrm{wt} \%$ [6]) is required to obtain an efficient flame retardant material. Moreover, its high loading is associated with reduced mechanical properties [7]. Thus, establishment of synergistic effect between ingredients is extremely vital to lower its content.

Polymer composites based on nanofiller is a popular solution in order to improve fire resistance, mechanical, thermal, electrical, and gas barrier properties of polymers [8-10]. For example, carbon nanotube and expandable graphite are greatly used as carbonization agents and 
suppressors for flammability of polymers, which are associated with a "liquid like" $\left(\mathrm{G}^{\prime} \sim \omega^{2}\right)$ or "solid-like" $\left(\mathrm{G}^{\prime} \sim \omega\right)$ behavior in storage modulus vis frequency during viscoelastic measurements [11-14]. In the case of layered fillers, well-accepted mechanisms for fire retardancy and gas barrier are the formation of thermal barrier $[8,15,16]$ and extended paths for gas molecules permeation [17], respectively. Moreover, the properties of the former and the latter are strictly correlated with each other. In other words, the higher the performance of the nanocomposite, the better the fire retardancy along with gas barrier will be as a consequence. On the other hand, efficiency of nanofiller in composites strongly depends on its geometric structure.

Graphene nanosheets consisting of thin two-dimensional sheets of carbon are a promising choice among nanofillers due to making flame retardant, electrically conductive, moisture barrier, and enhanced tensile strength nanocomposites materials. Graphene oxide (GO) and its' derivatives have attracted much more attention in this regards, as it is straightforward to synthesize them in large scale. Intense oxidation of graphene sheets during production of GO disturbs the original honeycomb network of $\mathrm{sp}^{2}$ carbon atoms, and even makes some oxidative debris due to oxidation of carbon network, making it an insulation materials. In order to retain the conductivity of graphenic sheets, at least partially, chemical reduction of GO has been widely used. Reduced graphene oxide ( $\mathrm{rGo}$ ) is also a layered form of carbon and oxygen [18-21]. Oxygenated functional groups of rGO are able to react with active sites of some polymer matrices resulting in an ideal interface between the rGO and matrix. As an example, the formation of chemical bonds between isocyanate groups of PU and hydroxyl groups of unmodified rGO contribute to a higher degree of exfoliation [22, 23] which eventually leads to better nanocomposite properties.

To the best of our knowledge, no work has been performed regarding the incorporation of $\mathrm{rGO}$ as carbonization agent into IFR to enhance the properties of PU composites. In the current work, the IFR system including microencapsulated ammonium polyphosphate (MCAPP) and melamine (MA) was blended with PU to obtain flame retardant and environmentally friendly composites, with rGO as a synergistic agent. We mainly focused on the morphology, thermal, flame retardancy, permeability, mechanical, electrical, viscoelasticity, and physical properties of the prepared IFR polyurethane (IFRPU)/rGO composites.

\section{Experimental section}

Materials

PU (Desmopan 5377 A) was purchased from Bayer Co., Ltd. (Germany). MCAPP (average size $10 \mu \mathrm{m}$ ) was provided from Hefei Keyan Co. (China). MA was supplied from Sigma-Aldrich Co. The IFR was composed of MCAPP and MA (the weight ratio was 2:1).

GO was synthesized based on the modified Hummers method [24] using expanded graphite (supplied by Asbury Graphite Mills, USA). The obtained GO particles were diluted using DI water $(\sim 1 \mathrm{mg} / \mathrm{ml})$ and mildly sonicated for $20 \mathrm{~min}$ in a bath sonicator, followed by probe sonication for $10 \mathrm{~min}$. Ultralarge GO sheets with a mean lateral size of more than $10 \mu \mathrm{m}$ were obtained. To reduce GO, hydrazine solution was added to the mixture in the weight ratio of $3: 1$ while stirring at $80^{\circ} \mathrm{C}$ for $24 \mathrm{~h}$. The mixture was poured into flat molds and dried in an oven at $50{ }^{\circ} \mathrm{C}$ for $6 \mathrm{~h}$ to produce rGO sheet [25]. Details of synthesis and characterization of rGO are given in previous works of one of us $[26,27]$.

Preparation of samples

PU, MCAPP, and MA granules were dried in a vacuum oven at $80{ }^{\circ} \mathrm{C}$ for $24 \mathrm{~h}$ prior to melt processing. They were fed into a twin-screw extruder (FEDDEM GmbH \& Co. $\mathrm{KG}$, Germany) at the screw speed of $60 \mathrm{rpm}$ at $140{ }^{\circ} \mathrm{C}$. The IFR was then poured and mixed at the same speed for 2 min. rGO was gradually added into the twin-screw extruder, while blending. The mixture was blended for $15 \mathrm{~min}$ and was allowed to cool at room temperature. After mixing, the samples were hot-pressed at about $150{ }^{\circ} \mathrm{C}$ under $10 \mathrm{MPa}$ for $10 \mathrm{~min}$ into sheets with the thickness of $3.0 \pm 0.1 \mathrm{~mm}$ for UL-94 and limiting oxygen index (LOI) test and $2.0 \pm 0.1 \mathrm{~mm}$ for DIN 4102 standard test method. The formulation of prepared samples is presented in Table 1.

\section{Measurements}

Wide-angle X-ray scattering (WXRD) of the samples was recorded on an X-ray diffractometer [EQUINOX3000, Inel Co., $\mathrm{Ltd}$ (French)], using $\mathrm{Cu} \mathrm{K} \alpha$ radiation $(\lambda=0.15418 \mathrm{~nm})$ at $40 \mathrm{kV}$ and $20 \mathrm{~mA}$.

Table 1 Formulations of Pure PU and IFRPU/rGO composites (by wt $\%)$

\begin{tabular}{lrcl}
\hline Samples & PU & IFR $^{\mathrm{a}}$ & rGO \\
\hline Pure PU & 100 & 0 & 0 \\
PU-0 & 80 & 20 & 0 \\
PU-0.5 & 80 & 19.5 & 0.5 \\
PU-1 & 80 & 19 & 1 \\
PU-2 & 80 & 18 & 2
\end{tabular}

${ }^{\text {a }}$ IFR contains MCAPP/MA blend at a weight ratio of 2:1 
The morphology of the fracture surface and char residues after LOI test was studied by Philips X130E scanning electron microscope (SEM) at acceleration voltage of $20 \mathrm{kV}$. First, the specimens of IFRPU/rGO composites were fractured in liquid nitrogen, and then sputter-coated with a conductive layer of gold.

LOI was measured according to ASTM D 2863. The used apparatus was an HC-2 oxygen index meter (Dynisco, USA). The vertical test was carried out on a UL-94 chamber (Concept Fire Testing, UK) according to the UL94 test standard. The dimensions of used specimens for the UL-94 and LOI tests were $130 \times 13 \times 3$ and $100 \times$ $6.5 \times 3 \mathrm{~mm}^{3}$. To measure burning times of various samples, $40 \times 10 \times 2 \mathrm{~mm}^{3}$ bars were prepared and burning time to 2-cm-mark lines was measured according to Clause 6.2.5 of DIN 4102 standard.

Fourier transform infrared spectra (FTIR) of the samples were obtained using Equinox 25 Bruker (Canada). Typically, 1-2 mg samples were mixed with $100 \mathrm{mg}$ of $\mathrm{KBr}$ powder and pressed into pellets. All the spectra are the average of 32 scans taken in the wavenumber range of $4000-400 \mathrm{~cm}^{-1}$.

Thermogravimetric analysis (TGA) was carried out using a thermoanalyzer instrument (Mettler Toledo, SDTA 851 ) at a linear heating rate of $10{ }^{\circ} \mathrm{C} / \mathrm{min}$ under a nitrogen and air flow. Samples have been tested in an alumina crucible with a mass of about $10.0 \mathrm{mg}$ (apart from rGO: $5 \mathrm{mg}$ ). The temperature reproducibility of the instrument was $\pm 1{ }^{\circ} \mathrm{C}$, while the mass reproducibility was $\pm 0.2 \%$.

The theoretical TGA curve was computed by linear combination between the TGA curves of Pure PU, IFR, and rGO. The formula is as follows [7]:

$$
\begin{aligned}
W_{\mathrm{th}}(\mathrm{T})_{\mathrm{IFRPU} / \mathrm{rGO}}= & x \times W_{\exp }(\mathrm{T})_{\mathrm{PurePU}}+y \times W_{\exp }(\mathrm{T})_{\mathrm{IFR}} \\
& +z \times W_{\exp }(\mathrm{T})_{\mathrm{rGO}} \quad x+y+z=1
\end{aligned}
$$

where $W_{\text {th }}(\mathrm{T})_{\text {IFRPU/rGO }}$ : theoretical TGA curve of the IFRPU/rGO composites; $W_{\exp }(\mathrm{T})_{\text {Pure PU: experimental TGA }}$ curve of the Pure PU; $W_{\text {exp }}(\mathrm{T})_{\text {IFR }}$ : experimental TG curve of IFR; $W_{\exp }(\mathrm{T})_{\mathrm{rGO}}$ : experimental TGA curve of $\mathrm{rGO} ; x, y$, and $z$ are the weight percentages of the Pure PU, IFR, and rGO in the composites, respectively.

The real-time FTIR (RTFTIR) were recorded using a Nicolet MAGNA-IR 750 spectrophotometer equipped with a heating device and a temperature controller. Powders of samples were mixed with $\mathrm{KBr}$ powders, and the mixture was pressed into a tablet, which was then placed in a ventilated oven. The temperature of the oven was raised at a heating rate of $10{ }^{\circ} \mathrm{C} / \mathrm{min}$.

Water swell (i.e., the degree of water absorption) was measured by preserving a film in water. The water swell (\%) was calculated by the following equation, where $W_{\mathrm{o}}$ is the original film weight and $W$ is the film weight after water absorption:

$\%$ swell $=\frac{W-W \circ}{W \circ} \times 100$.

Gas permeability tests were carried out using a constant volume-variable pressure apparatus at $35^{\circ} \mathrm{C}$ on disks (diameter: $4.2 \mathrm{~cm}$ ) cut from composite films. $\mathrm{O}_{2}$ flow was fed to one side of the specimen at $1 \mathrm{~atm}$ and temporal pressure change in the opposite, evacuated side was recorded.

The surface electrical conductivity at room temperature was measured with a ZC36 high resistance meter. Measurements were repeated on three different areas of the composite films to ensure sample uniformity and their averages are reported.

Mechanical properties of the samples were tested with a Galdabini Sun-2500 Universal Testing machine according to ASTM D 683. At least three samples were tested to obtain average values. Shore A hardness was measured using an indentation hardness tester according to ASTM D2240-75.

Rheological properties were evaluated using an ARES (Anton Paar, Germany) with parallel plate geometry of $25 \mathrm{~mm}$ in diameter. The linear viscoelastic region was determined by monitoring storage modulus in dynamic strain amplitude sweep experiment. Dynamic frequency sweeping tests were measured with the frequency $(\omega)$ from $0 / 01$ to $1000 \mathrm{rad} / \mathrm{s}$.

\section{Results and discussion}

Dispersion of rGO and composites morphology

WAXS was performed to analyze the state of dispersion of rGO in the matrix (Fig. 1). After incorporation of IFR into PU, the main diffraction peaks were observed at $2 \theta$ values of $12.79,14.8,21.8,27.7,29,30$ (assigned to MCAPP) and 15.7, 26, 30.7 (assigned to MA) [7].

The absence of any diffraction peaks corresponding to the interlayer spacing of rGO suggests an exfoliated morphology of rGO platelets in IFRPU.

SEM images of the fractured surfaces of the composites are shown in Fig. 2. As it can be seen, there is no obvious agglomeration of additives and $\mathrm{rGO}$ with layered structure is uniformly dispersed in PU matrix. It has recently been implied that the presence of filler pull-out is an indication for better matrix-filler interfacial adhesion [28, 29]. The extremely small thickness of single layer $(\sim 0.34 \mathrm{~nm})$ and surface functional groups of rGO lead to strong interfacial interaction with PU chains, illustrated by circles as adhered PU to the pulled-out rGO in Fig. 2 [28, 29]. Additionally, 


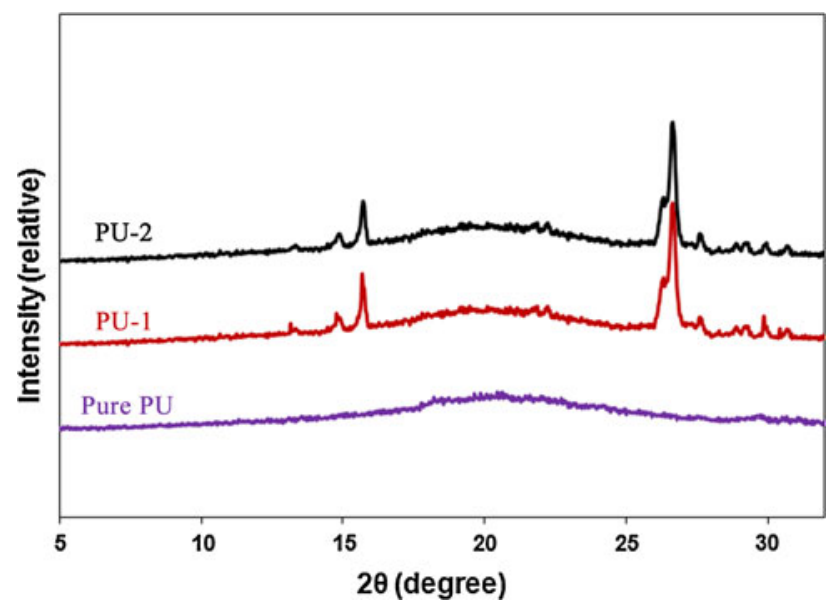

Fig. 1 WXRD scattering patterns for the Pure PU and IFRPU/rGO composites

apart from rGO content (i.e., whether 1 or $2 \%$ ), the morphologies of the fracture surfaces are pretty identical in both cases, indicating that $\mathrm{rGO}$ is uniformly dispersed without discernable sign of filler-matrix debonding or aggregation [30-32]. Indeed, these observations along with WAXS results demonstrate that even without surface modification of $\mathrm{rGO}$, interfacial interactions had been strong enough to make dispersion level excellent [33-35].

\section{Flame retardancy of Pure PU and IFRPU/rGO} composites

Table 2 and Fig. 3 present the results of LOI values and UL-94 of the IFRPU/rGO composites. Despite the fact that flame retardancy is notably enhanced by the introduction of MCAPP and MA, it is not still categorized in UL-94 V0 rating. Moreover, it can be seen that LOI values of the composites enhance with rGO increment. LOI was increased from 22.0 to 34.0 by addition of $2 \mathrm{wt} \% \mathrm{rGO}$ and $18 \mathrm{wt} \%$ IFR. The results of DIN 4102 standard support LOI values as well. Utilizing high amount of MCAPP (30 wt\%), Ni et al. [36] could prepare PU composites possessing UL-94 V0 rating. In another study, Duquesne et al. [6] reached LOI value of 34 by incorporation of $27 \mathrm{wt} \%$ APP. As compared to the results of abovementioned studies, one can infer that this IFR mixture along with rGO effectively ameliorates flame retardancy of PU. In fact, it is deemed that rGO has acted as effective carbonization agents for PU, which not only assists the formation of a superior protective char layer but also results in self-extinguishing phenomenon. Moreover, rGO apparently has had a synergism effect with other components which will be discussed in the following sections of this paper.

Figure 4 shows the SEM images of chars from PU-1 and PU-2. The chars swell beside the flame and expand in a leaf-like overlapped morphology. Additionally, chars are very compact that not only reduce the heat transfer between the heat source and the composite surface, but also limit the diffusion of oxygen into PU bulk.

\section{FTIR analysis}

On one hand, mechanical properties of polymer composites containing nanofiller are greatly influenced by its dispersion. On the other hand, uniform dispersion of nanofiller in the host polymer strongly depends on interfacial interactions [28]. Hence, FTIR spectroscopy was used to assess the presence of such interactions (shown in Fig. 5). Interpretation of interaction between ammonium polyphosphate and other components was ignored owning to its encapsulation by PU. Therefore, comparing the spectra of Pure PU with PU-0 reveals interaction between MA and PU, whereas comparing the spectra of PU-0 and PU-2 clarifies the hydrogen bonding between PU and rGO. Compared with the spectra of Pure PU, three sharp peaks $(1652,1556$, and $1438 \mathrm{~cm}^{-1}$ ) have disappeared while two new peaks (1757 and $1593 \mathrm{~cm}^{-1}$ ) have appeared in PU-0. This can be attributed to the absorption of urethane linkages between MA component and PU resulting in miscibility of PU-MA [37]. On the other hand, when the spectra of PU-0 and PU2 are compared, one can observe an intense shift in
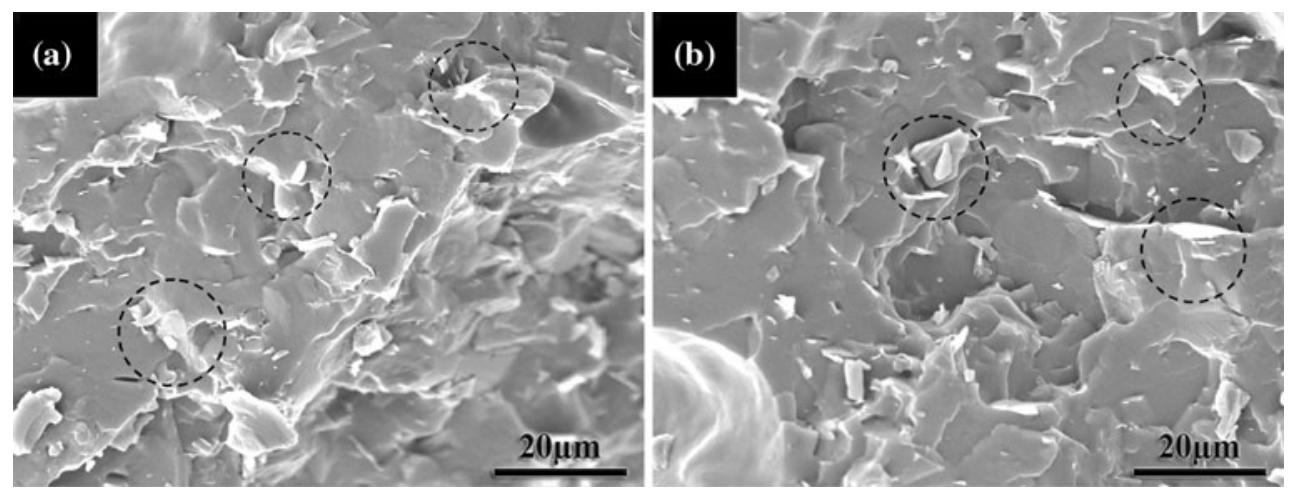

Fig. 2 SEM images of PU-1 (a) and PU-2 (b); circles stand for regions where PU chains adhered to the pulled-out rGO due to strong interactions 
Table 2 The flame retardancy of IFRPU/rGO composites

\begin{tabular}{lllll}
\hline Samples & LOI (\%) & UL-94 rating & Dripping & Time of burning (s) \\
\hline Pure PU & 22.0 & Burning & Yes & 42 \\
PU-0 & 29.0 & $\mathrm{~V}_{1}$ & Yes & 78 \\
PU-0.5 & 31 & $\mathrm{~V}_{1}$ & No & Self-extinguished \\
PU-1 & 32 & $\mathrm{~V}_{1}$ & No & Self-extinguished \\
PU-2 & 34 & $\mathrm{~V}_{0}$ & No & Self-extinguished \\
\hline
\end{tabular}

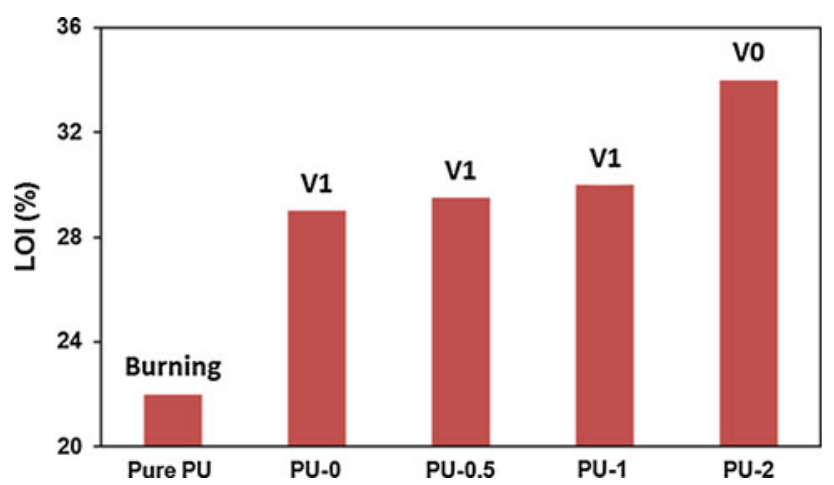

Fig. 3 Effect of rGO on the LOI values and UL-94 results of the Pure $\mathrm{PU}$ and IFRPU composites

carbonyl group of PU. Carbonyl group of PU shows absorption peaks ranging from 1750 to $1650 \mathrm{~cm}^{-1}$ and it is widely reported that if this group participates in hydrogen bonding, its peak will shift to the lower value [1]. After introduction of $2 \mathrm{wt} \%$ of rGO, carbonyl peak shifted from 1757 to $1707 \mathrm{~cm}^{-1}$ indicating that a strong hydrogen bonding exists between rGO and PU which not only promotes the level of rGO dispersion but also results in improved properties of composite.

Thermal stability of Pure PU and IFRPU/rGO composites

The typical TGA and DTG traces for Pure PU and IFRPU/ rGO composites under nitrogen atmosphere are given in
Fig. 6. The initial decomposition temperature $\left(T_{\mathrm{d},-5 \%}\right)$ can be considered as the temperature at which the weight loss is $5 \%$. The relative thermal stability of samples was compared by the temperatures of $5 \%\left(T_{\mathrm{d},-5 \%}\right)$ and $75 \%$ $\left(T_{\mathrm{d},-75 \%}\right)$ weight loss, the temperature of maximum rate of weight loss $\left(T_{\max }\right)$, and the percent of char yield at $600{ }^{\circ} \mathrm{C}$. These data are listed in Table 3.

Pure PU had a three-step degradation process at $320-380,380-420$, and $500-600{ }^{\circ} \mathrm{C}$. The first step is ascribed to the dimerization and trimerization reaction of isocyanates [38]; the second stage is mainly attributed to de-polymerization of PU to form isocyanate, polyol, the primary or secondary amine, olefin, and carbon dioxide; and finally the last degradation stage is assigned to the decomposition of hard segment [39].

Similarly, though with some variations, thermal degradation of IFRPU/rGO composites had three stages at $250-310,310-380$, and $500-600{ }^{\circ} \mathrm{C}$ which are, respectively, assigned to the weight loss of MA and MCAPP [39, 40], dimerization and trimerization reaction of isocyanates [38], and decomposition of hard segment.

As compared to the Pure PU, the $T_{\mathrm{d}},-5 \%$ and $T_{\max }$ (related to the first stage of degradation) of IFRPU/rGO composites are lower. This is because of the breakage of weak $\mathrm{P}-\mathrm{C}$ bond of MA and formation of polyphosphoric acid (as strong Lewis acid catalyst) which accelerates the decomposition [41] not because of rGO incorporation. In fact, besides the fact that IFR systems have detrimental effect on mechanical properties [7], they also have catalyzing effect on the decomposition of PU matrix in lower temperatures.

However, as the content of rGO increases from 1 to $2 \mathrm{wt} \%, T_{\mathrm{d},-5 \%}$ and $T_{\max }$ of IFRPU/rGO composites increase from 276 to 284 and 327 to $333{ }^{\circ} \mathrm{C}$, respectively. The improvement of thermal stability is attributed to the high surface area and good dispersion of rGO sheets induced by strong interactions between PU and rGO [28, 42,43 ] as well as tortuous path effect of rGO which delays the escape of volatile degradation products and promotes
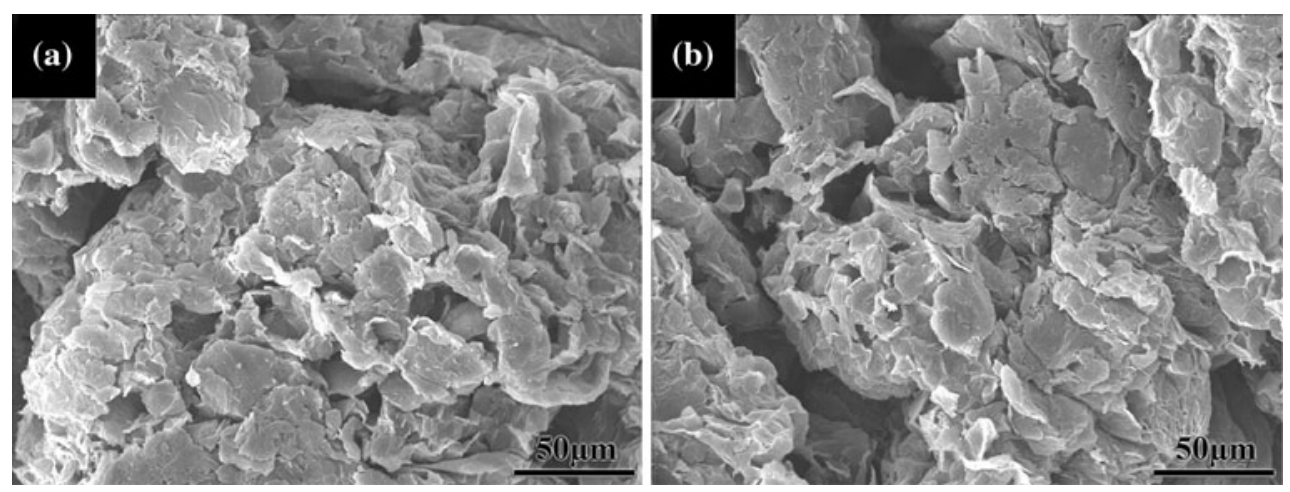

Fig. 4 SEM images of the char residues of PU-1 and PU-2 


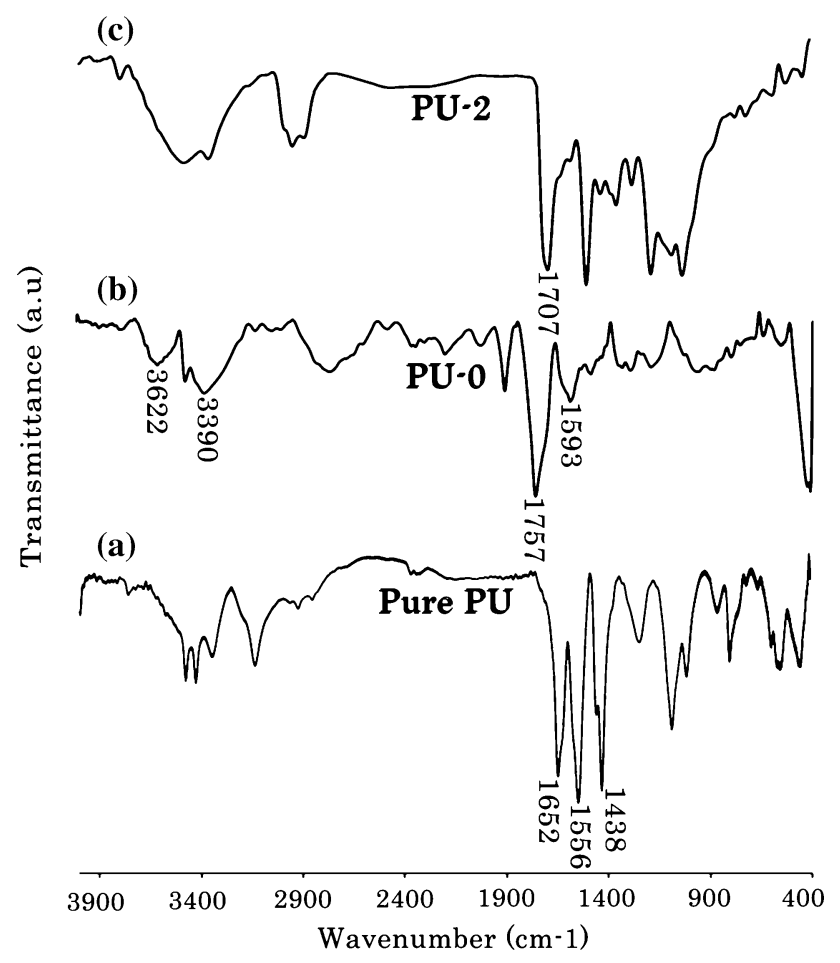

Fig. 5 FTIR spectra of Pure PU (a), PU-0 (b), and PU-2 (c)

char formation [44]. Another reason for this improvement is that the absorbed thermal energy first raises the internal temperature, then melts the strain-induced PU crystallites
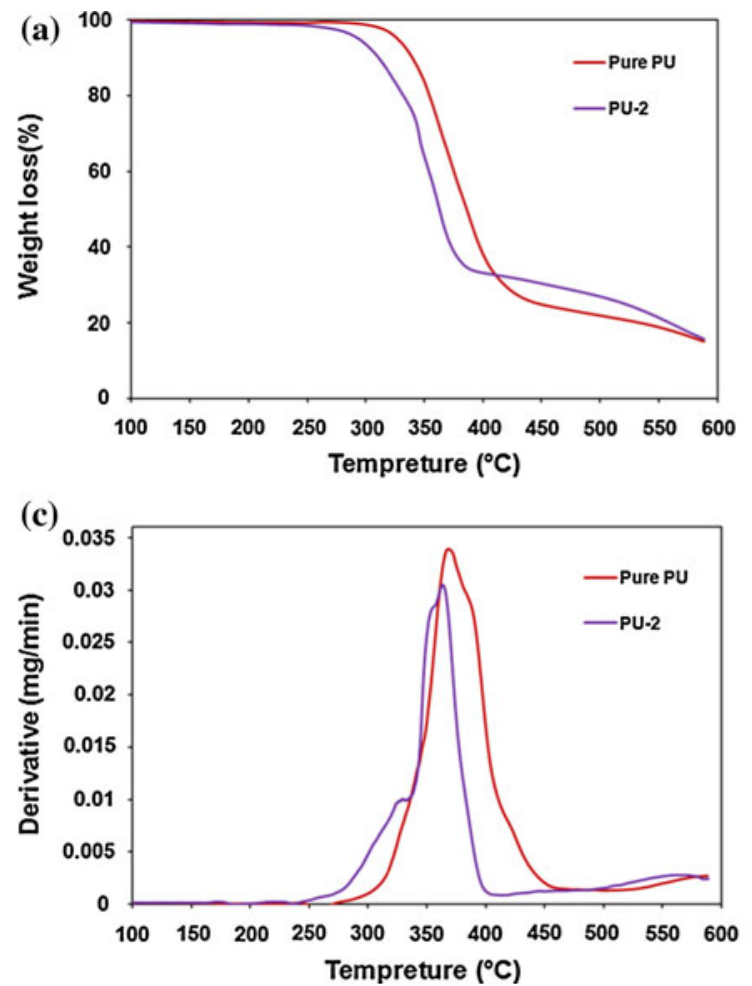

(act as physical crosslinks), and finally reduces the permeation of flammable gases [23, 45-47].

Figure 7 shows the TGA curves of Pure PU and PU-2 under air and nitrogen flow. In contrast to the nitrogen flow, weight loss of Pure PU under air atmosphere showed one broad peak ranging from 300 to $410{ }^{\circ} \mathrm{C}$. More importantly, $T_{\max }$ of Pure PU under air atmosphere $\left(360{ }^{\circ} \mathrm{C}\right)$ was higher than its corresponding value under nitrogen flow $\left(339{ }^{\circ} \mathrm{C}\right)$. Correspondingly, $T_{\max }$ of PU-2 under air atmosphere was greater than its value under nitrogen flow.

For a better understanding of the oxidation phenomenon, TGA curves of Pure PU and PU-2 (Fig. 7a, b) under nitrogen and air atmosphere were compared. Regarding the Pure PU, the amount of the residue between 270 and $410{ }^{\circ} \mathrm{C}$ in thermo-oxidative conditions is higher than that under inert gas. In fact, the oxygen contributes to the stabilization of the material in $300-540{ }^{\circ} \mathrm{C}$ and its degradation in $410-600{ }^{\circ} \mathrm{C}$ [2]. In both cases, the competition between oxidation of the material (which leads to a decrease in the mass) and reaction with oxygen (which increases the weight retardation of mass loss) may be considered under air in $270-400{ }^{\circ} \mathrm{C}$. Additionally, it was found that the char residue at $600{ }^{\circ} \mathrm{C}$ was increased from 6.5 to 14.5 with addition of IFR and rGO. While it raised from 14.5 to 19.5 , as the rGO content increased from 1 to $2 \mathrm{wt} \%$ (Table 3). These prove that the IFR and rGO may have a synergistic
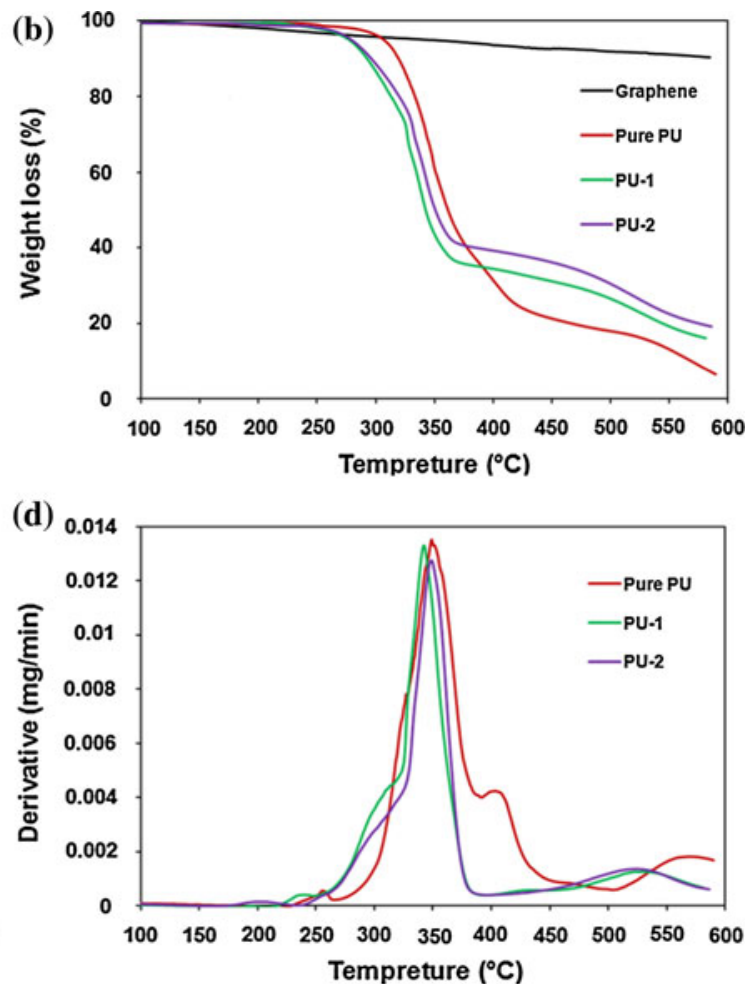

Fig. 6 a TG and b DTG traces for Pure PU and PU-2 in air flow, $\mathbf{c}$ TG and d DTG thermograms for Pure PU and IFRPU/rGO composites in nitrogen atmosphere 
Table 3 TGA data of Pure PU and IFRPU/rGO composites in nitrogen atmosphere

\begin{tabular}{lllll}
\hline Samples & $T_{\mathrm{d},-5 \%}\left({ }^{\circ} \mathrm{C}\right)$ & $T_{\mathrm{d},-75 \%}\left({ }^{\circ} \mathrm{C}\right)$ & $T_{\max }\left({ }^{\circ} \mathrm{C}\right)$ & $\begin{array}{l}\text { Char residue }(\%) \\
\text { at } 600{ }^{\circ} \mathrm{C}\end{array}$ \\
\hline Pure PU & 301 & 420 & 339 & 6.5 \\
PU-1 & 276 & 517 & 327 & 14.5 \\
PU-2 & 284 & 534 & 333 & 19.25 \\
\hline
\end{tabular}

effect on char formation, which can help to improve the flame retardancy of PU.

For further investigation of IFR/rGO synergistic effect, weight difference between the experimental and theoretical TG curves of PU-2 was compared (Fig. 8). It was found that both $T_{\mathrm{d},-5 \%}$ and residue at $600{ }^{\circ} \mathrm{C}$ are higher than those in the calculated ones suggesting the improvement of thermal stability. However, at the temperatures of 280 to $430{ }^{\circ} \mathrm{C}$, the experimental curves showed fast thermal degradation with respect to the calculated ones. MA can form phosphoric anhydrides or the related acids at higher decomposition temperature, and these resultants also promote the char formation [7]. This char with phosphorcarbonaceous structure is more stable than that with carbonaceous structure obtained from Pure PU without IFR particles. Since the calculated curves are obtained by linear combination among the non-interacting individual components in the system [7], the catalyzing effect of IFR on the decomposition of PU indeed occurred. Besides, at higher temperature $\left(>410{ }^{\circ} \mathrm{C}\right)$, the experimental curves exhibited higher thermal stability and char yield as compared with the calculated ones, which confirm the presence of a synergism between IFR and rGO on flame retardancy.

\section{Thermal degradation of Pure PU and IFRPU/rGO} composites

Dynamic FTIR was employed to investigate the thermal degradation process of Pure PU and PU-2 composite. The

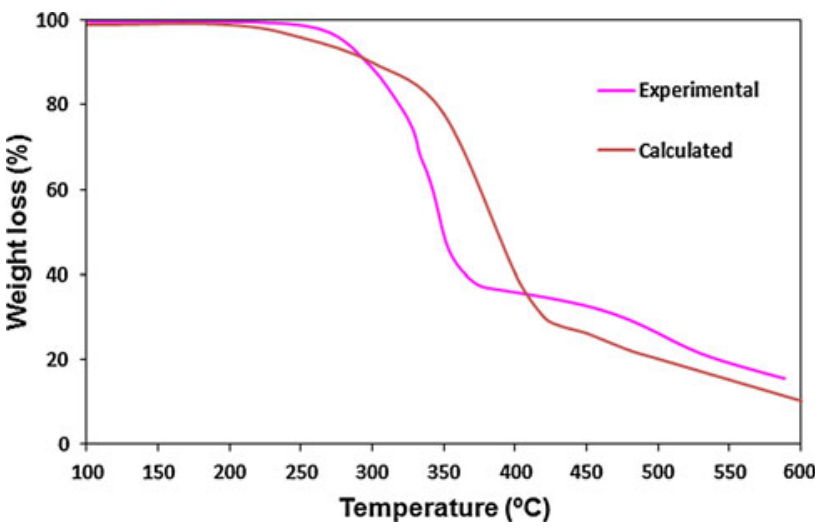

Fig. 8 Weight difference between the experimental and theoretical TG curves for PU-2

FTIR spectra of Pure PU at different degradation temperatures are shown in Fig. 9. The characteristic absorption bands of PU chains are at 1027, 1438, 1556, 1652, 2933, 3137, 3357, and $3467 \mathrm{~cm}^{-1}$ which are, respectively, assigned to the stretching vibration of $\mathrm{C}-\mathrm{O}-\mathrm{C}$ groups, the stretching vibration of $\mathrm{CH}_{2}$ groups, the stretching vibration of the urethane amide bond, hydrogen-bonded urea carbonyl groups, the asymmetric stretching vibration of $\mathrm{C}-\mathrm{H}$ bond, the isocynate groups, the stretching $\mathrm{N}-\mathrm{H}$ hydrogenbonded, and the free stretching $\mathrm{N}-\mathrm{H}$ bond.

At $250{ }^{\circ} \mathrm{C}$, the spectrum of the residue demonstrates some changes. The band around $1730 \mathrm{~cm}^{-1}$ attributed to the $\mathrm{C}=\mathrm{O}$ of the urethane function is no longer observed. It can be proposed that the first step of the degradation consists of the reverse reaction of polyaddition resulting in the formation of alcohol and isocyanate groups which is in agreement with the literature data [48]. On the other hand, at $310{ }^{\circ} \mathrm{C}$, a band around $1637 \mathrm{~cm}^{-1}$ attributed to urea function appeared. As a consequence, it may be suggested that the isocyanate obtained from depolymerization and the unreacted original isocyanate which are very reactive dimerize. This fact is associated with the production of carbodiimide and $\mathrm{CO}_{2}$ [2]. Carbodiimide should further
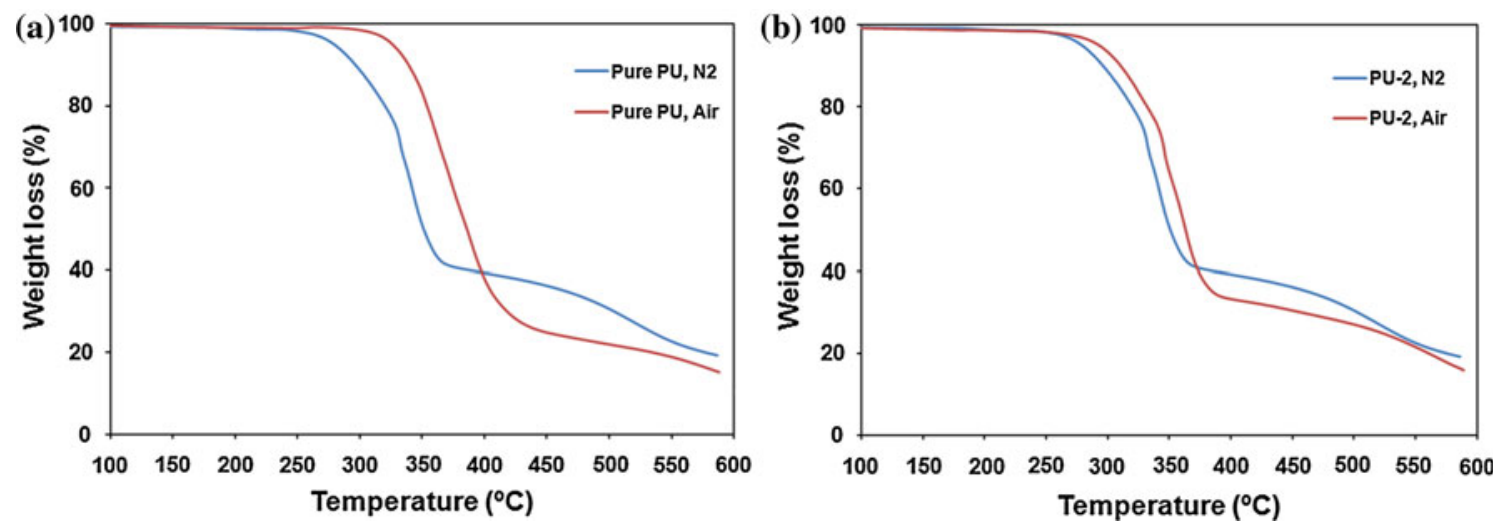

Fig. 7 TGA thermograms of a Pure PU b PU-2 under nitrogen and air atmospheres 


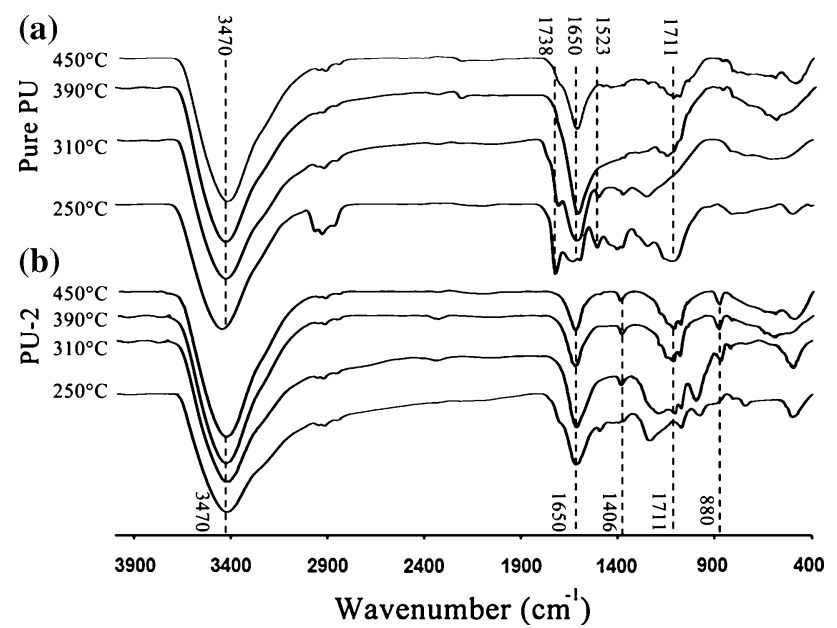

Fig. 9 Dynamic FTIR spectra of $a$ Pure PU, and $b$ PU-2 composite at different temperatures

react with alcohol to give substituted urea. In the last step of degradation, when Pure PU degrades slowly, the intensity of urea bands decreased, this fact may be leading to the formation of a chars with carbonaceous structure.

In the case of PU-2, at $250{ }^{\circ} \mathrm{C}$, the bands at 3472,3425 , and $1652 \mathrm{~cm}^{-1}$ corresponding to $\mathrm{NH}_{2}$ group dramatically decrease. This can be caused by the release of ammonia from MA. While the temperature rises up to $310{ }^{\circ} \mathrm{C}$, the intensity of the absorption peaks at 2931, 1730, 1706, 1313 , and $1078 \mathrm{~cm}^{-1}$ nearly decreases, indicating that the main decomposition of Pure PU occurs around this temperature. However, the absorption peaks at 2970, 2931, 1635 , and $1027 \mathrm{~cm}^{-1}$ for Pure PU still exist at $390{ }^{\circ} \mathrm{C}$. The presence of IFR catalyzes the degradation of PU matrix, which corresponds well with TGA results.

At higher temperature $\left(\geq 390{ }^{\circ} \mathrm{C}\right)$, four new peaks at $1406,1267,1171$, and $880 \mathrm{~cm}^{-1}$ appeared, while these peaks are not visible in the spectra of Pure PU. The peaks at 1406 and $1267 \mathrm{~cm}^{-1}$ can be ascribed to the stretching vibration of $\mathrm{P}=\mathrm{O}$ and $\mathrm{PO}_{2} / \mathrm{PO}_{3}$ in phosphate-carbon complexes [49]. The peaks at 1171 and $880 \mathrm{~cm}^{-1}$ belong to the stretching vibrations of $\mathrm{P}-\mathrm{O}-\mathrm{P}$ bond, and this indicates the formation of thermal stable polyphosphate, such as $\mathrm{P}_{2} \mathrm{O}_{5}$ and $\mathrm{P}_{4} \mathrm{O}_{10}$ [50]. The presence of polyphosphate catalyzes the formation of char, which can prevent the materials from further degradation during combustion.

\section{Transition behavior of Pure PU and IFRPU/rGO} composites

The DSC analysis of Pure PU and IFRPU/rGO composites are shown in Fig. 10 and Table 4. One glass transition $\left(T_{\mathrm{g}}\right)$ and three endothermic transition regions are shown at 90-140 ${ }^{\circ} \mathrm{C}$ (endothermic I), $180-210{ }^{\circ} \mathrm{C}$ (endothermic II), and $230-270{ }^{\circ} \mathrm{C}$ (endothermic III). $T_{\mathrm{g}}$ was increased by

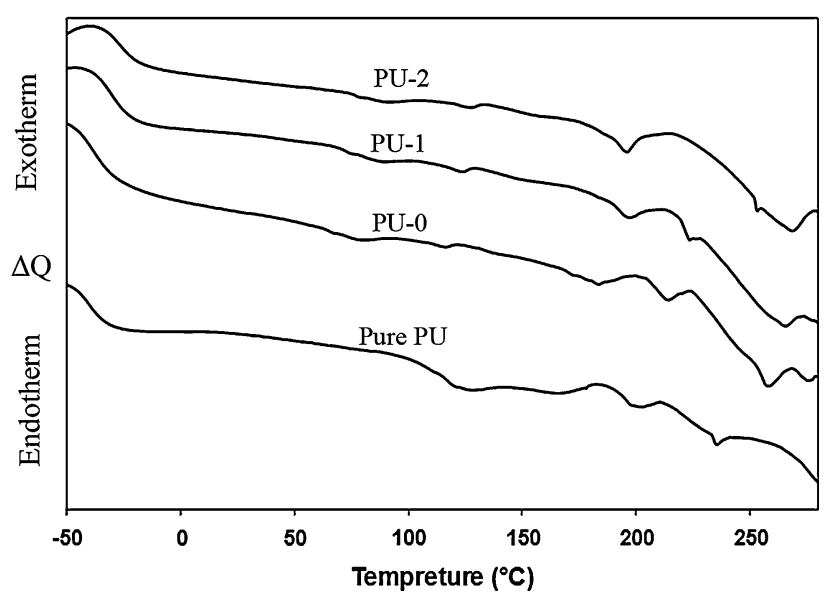

Fig. 10 DSC curves of Pure PU, and IFRPU/rGO composites

addition of rGO thanks to the interaction of $\mathrm{PU}$ chains with rGO. This shows that Pure PU was reinforced by rGO while the chain mobility of the soft segment was reduced in the presence of rGO [11]. Three endothermic peaks are assigned to various morphologies of PU hard segment. Incorporation of IFR components and rGO in PU led to some variations in transition regions which are due to PU/ $\mathrm{MA}$ and PU/rGO interactions. Transition I can be assigned to short-range hard segment morphology that shifted to the lower temperature with IFR incorporation, while it disappeared by rGO increment. Transition II is attributed to dissociation of long-range ordering in micro-phase hard segment which increased by rGO and IFR incorporation. Transition III is ascribed to the hard segment melting point which rose by addition of rGO [51]. The reason for this is strong interaction between PU/rGO which enhances hard segment arrangements.

\section{IFRPU/rGO composites properties}

Water-resistant, electrical, gas barrier and mechanical properties of polymers can dramatically be influenced by rGO addition. In this section, we discuss improved physical properties of IFRPU reinforced with rGO.

Table 5 shows that the presence of impermeable rGO in composites reduces the water swell (i.e., improves the resistance of composites to water). The increase of the mean free path for water molecules to pass through the matrix of IFRPU/rGO composites is responsible for increment in resistance to water [52].

The surface resistance of IFRPU/rGO is shown in Table 5. Incorporation of rGO could notably improve the electrical conductivity of PU films (reduced resistance). This reinforcement is attributed to the covalently hydrogen bonding between PU chains and rGO surface.

$\mathrm{O}_{2}$ permeability of IFRPU/rGO films at $35{ }^{\circ} \mathrm{C}$ is summarized in Table 5. It was remarkably reduced in the 
Table 4 Glass transition, melting point, heat of fusion, and total heat of fusion of Pure $\mathrm{PU}$ and IFRPU/rGO composites

\begin{tabular}{|c|c|c|c|c|c|c|c|c|}
\hline \multirow[t]{2}{*}{ Samples } & \multirow[t]{2}{*}{$T_{\mathrm{g}}\left({ }^{\circ} \mathrm{C}\right)$} & \multicolumn{3}{|l|}{$T_{\mathrm{m}}\left({ }^{\circ} \mathrm{C}\right)$} & \multicolumn{3}{|c|}{$\Delta H_{\mathrm{f}}(\mathrm{J} / \mathrm{g})$} & \multirow[t]{2}{*}{$\Delta H_{\mathrm{f}, \text { Total }}(\mathrm{J} / \mathrm{g})$} \\
\hline & & I & II & III & I & II & III & \\
\hline Pure PU & -40.05 & 120.07 & 197.70 & 235.07 & 8.98 & 0.86 & 2.47 & 12.31 \\
\hline PU-0 & -37.83 & 118.19 & 198.86 & 256.21 & 7.56 & 1.65 & 8.42 & 17.63 \\
\hline PU-1 & -32.26 & - & 202.58 & 260.68 & - & 2.09 & 8.67 & 10.76 \\
\hline PU-2 & -28.85 & - & 206.12 & 269.41 & - & 2.24 & 8.96 & 11.2 \\
\hline
\end{tabular}

Table 5 Physical properties of Pure PU and IFRPU/rGO composites

\begin{tabular}{llllllll}
\hline Samples & \multicolumn{3}{l}{ Water swell $(\%)$ after } & & \multicolumn{2}{c}{ Oxygen permeability } & Conductivity (Scm-1) \\
\cline { 2 - 5 } & 1 day & 2 day & 3 day & 4 day & 5 day & & {$\left[\mathrm{cm}^{3}(\mathrm{STP}) / \mathrm{cm}-\mathrm{s}-\mathrm{cmHg}\right]$} \\
\hline Pure PU & 9.6 & 18.2 & 24.3 & 30.1 & 36.5 & $4.31 \times 10^{-11}$ & $1.14 \times 10^{-11}$ \\
PU-0 & 9.1 & 17.5 & 20.3 & 27.2 & 32.6 & $4.01 \times 10^{-11}$ & $1.18 \times 10^{-11}$ \\
PU-0.5 & 6.3 & 10.2 & 13.5 & 15.1 & 17.1 & $2.25 \times 10^{-11}$ & $6.25 \times 10^{-10}$ \\
PU-1 & 7.4 & 11.8 & 14.7 & 16.3 & 19.1 & $8.76 \times 10^{-12}$ & $3.08 \times 10^{-9}$ \\
PU-2 & 8.5 & 13.2 & 16.1 & 19.3 & 22.4 & $4.13 \times 10^{-12}$ & $2.19 \times 10^{-8}$ \\
\hline
\end{tabular}

presence of rGO such that there was $90 \%$ decrease in $\mathrm{O}_{2}$ permeability at $2 \mathrm{wt} \%$ rGO. Doubtless, exfoliated rGO served as effective diffusion barriers in polymeric membranes. Indeed, a percolating network of platelets provides a "tortuous path" which inhibits molecular diffusion through the matrix, thus resulting in reduced permeability. Besides that, on one hand, orientation of the platelets may further enhance barrier properties perpendicular to their alignment; on the other hand, the high platelet aspect ratios of rGO decline composite [53].

Data for the tensile strength, elongation at break, modulus, and shore A of Pure PU and IFRPU/rGO composites are summarized in Table 6. It can be seen that tensile strength become worse after addition of $20.0 \mathrm{wt} \%$ IFR. As discussed before [54, 55], IFR additives at high loading usually cause a negative impact on the mechanical properties of the composites. However, the incorporation of rGO exhibits reinforcement effect. The main reason for this is good level of dispersion which arises from the presence of strong interaction between rGO and matrix (discussed in "FTIR analysis" section). The folded and wrinkled structure of rGO might also be responsible for the better polymer chains adhesion to the rGO. All of these lead to superior load transfer from the matrix to rGO which finally result in the improvement of mechanical properties. From another point of view, since lack of agglomeration and excellent dispersion of fillers in matrix have strong positive impact on tensile strength, one can implicitly relate the improvement of those results to the homogeneous dispersion of rGO in the PU matrix. In other words, improved tensile strength can be indirectly considered as a useful evidence for examining the filler dispersion. It should be noted that, if the dispersion is good, rGO begin to effectively affect the hard segment domains through physical cross-linking, arising from hydrogen bonding between hydroxyl groups of rGO and urethane groups of PU [56]. The shore A hardness is also enhanced with rGO increment as a consequence of reinforcement effect of well-dispersed rGO (Table 6).

\section{Viscoelasticity properties}

Viscoelastic or rheological tests are widely used to study microstructure of nanocomposites and quantify dispersion of rGO [57, 58]. Figure 11a shows the shear storage modulus, $\mathrm{G}^{\prime}$, from small strain oscillatory shear versus frequency for IFRPU/rGO composites at $140{ }^{\circ} \mathrm{C}$. At 1 and $2 \mathrm{wt} \% \mathrm{rGO}, \mathrm{G}^{\prime}$ becomes independent of frequency at low frequency, which is a sign of solid-like network formation. This demonstrates the reinforcement effect of rGO in PU matrix and the presence of three-dimensional physical network (i.e., percolation regime) in these composites. In percolation regime, power law scaling describes dependency of $G$ ' to the concentration $\varphi$ of the particles as follows: [59, 60]

Table 6 Mechanical properties of Pure PU and IFRPU/rGO composites

\begin{tabular}{lllcl}
\hline Samples & $\begin{array}{l}\text { Tensile } \\
\text { strength (Mpa) }\end{array}$ & $\begin{array}{l}\text { Elongation } \\
\text { at break (\%) }\end{array}$ & Modulus & $\begin{array}{l}\text { Shore A } \\
\text { hardness }\end{array}$ \\
\hline Pure PU & 6.45 & 385.34 & 5.46 & 75 \\
PU-0 & 5.41 & 321.87 & 6.23 & 77 \\
PU-0.5 & 5.75 & 288.24 & 8.53 & 80 \\
PU-1 & 6.18 & 249.63 & 13.17 & 86 \\
PU-2 & 6.51 & 218.91 & 16.56 & 92 \\
\hline
\end{tabular}



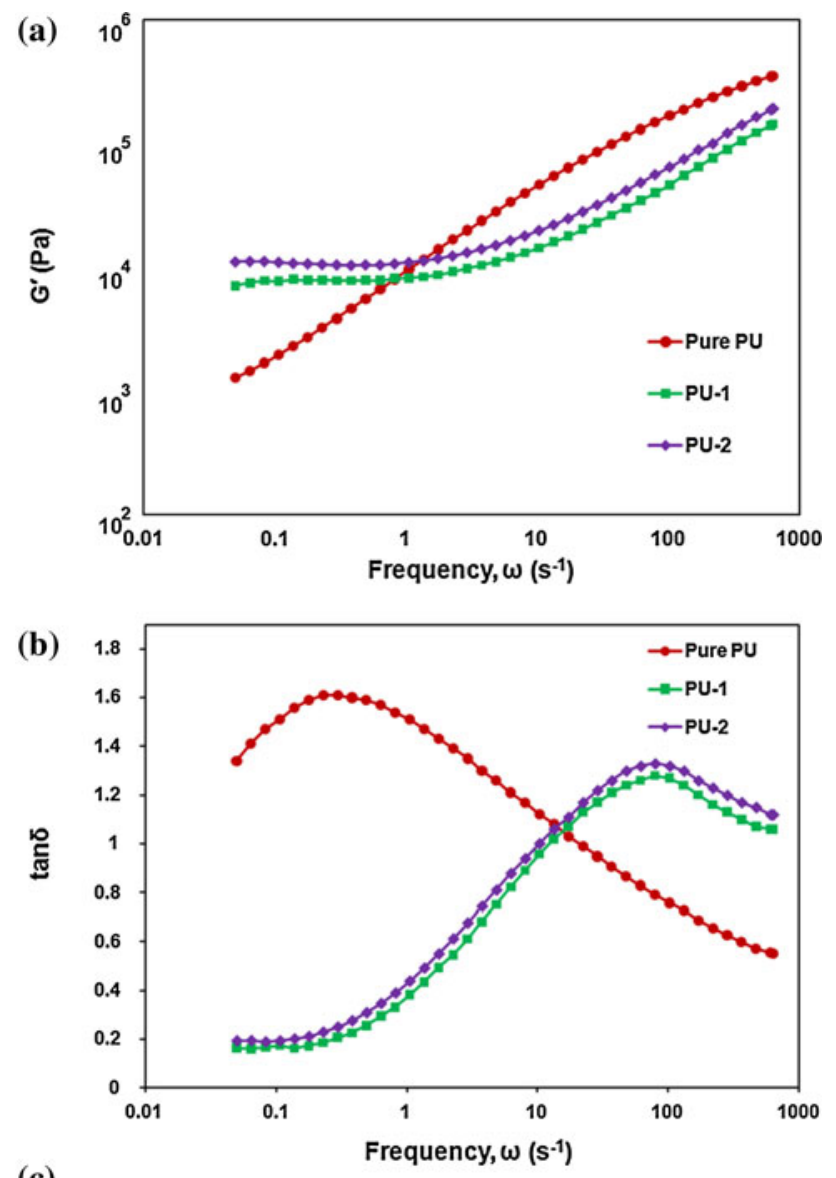

(c)

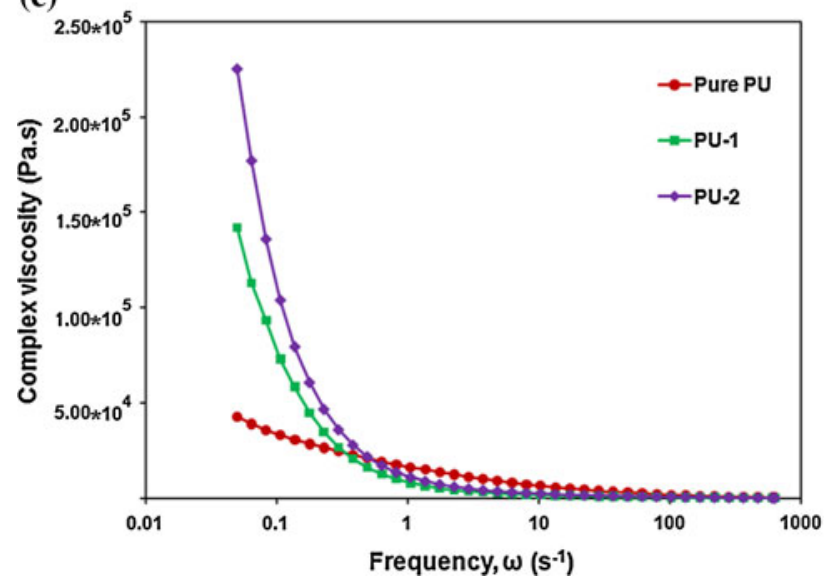

Fig. 11 Frequency dependence of $\mathbf{a} \mathrm{G}^{\prime}, \mathbf{b}$ damping factor, and $\mathbf{c} \eta^{*}$ of Pure PU and IFRPU/rGO composites performed at $140{ }^{\circ} \mathrm{C}$

$\mathrm{G}^{\prime} \propto\left(\varphi-\varphi_{\text {perc }}\right)^{v}$

$\varphi_{\text {perc }}$ and $v$ stand for the percolation threshold and power law exponent, respectively. $\varphi_{\text {perc }}$ of rGO can be experimentally determined from plot of low-frequency $\mathrm{G}^{\prime}$ versus $\varphi-\varphi_{\text {perc }}$. In extreme oblate/prolate limits, the percolation threshold is inversely proportional to the particle aspect ratio. By a rough estimation (i.e., considering that particles are randomly oriented, monodispersed, and disk-shaped), Ren et al. [61] discovered a relationship between $A_{\mathrm{f}}$ and $\varphi_{\text {perc }}$ as follows:

$A_{\mathrm{f}}=\frac{3 \varphi_{\text {sphere }}}{\varphi_{\text {perc }}}$,

where $\varphi_{\text {sphere }}=0.29$, the onset of interpenetrating percolation, randomly packed spheres [62]. $\varphi_{\text {perc }}$ was determined by using the results of Fig. 11a. Subsequently, Eq. 2 gives $A_{\mathrm{f}}=162$, which is in good agreement with the gas permeability results. Another parameter derived by rheological tests is relaxation time $(\tau)$ of polymer chains which can be severely affected by the addition of nanofiller [63]; it can be determined by the reciprocal of frequency where $\mathrm{G}^{\prime}$ intersects with $\mathrm{G}^{\prime \prime}$ (i.e., where $\tan \delta=1$ ) (Fig. 11b). $\tau$ of neat $\mathrm{PU}$ chains at $140{ }^{\circ} \mathrm{C}$ is about $0.068 \mathrm{~s}$, while adding rGO brought about an extended $\tau$ value. These results also suggest that the presence of rGO strongly limits the relaxation of polymer chains due to a high aspect ratio. Figure 11c presents frequency dependence of complex viscosity $\left(\eta^{*}\right)$; the $\eta^{*}$ values display a similar trend to that of $\mathrm{G}^{\prime}$ and are significantly increased by adding rGO especially in the low frequencies such as $0.01 \mathrm{rad} / \mathrm{s}$. It is noteworthy to point out that PU-2 which had improved flame retardancy was accompanied with increased $\mathrm{G}^{\prime}$ or $\eta^{*}$ at low frequencies; this suggest that flammability and linear viscoelastic properties are closely related.

\section{Conclusion}

The IFR PU composites exhibited improved flame retardancy, thermal stability, gas barrier, as well as mechanical properties. It was found that both thermal stability and mechanical properties become worse by the addition of MA and MCAPP. However, introduction of rGO not only compensated those, but also improved other properties. Employing $18 \mathrm{wt} \%$ IFR along with $2 \mathrm{w} \%$ rGO, PU composite reached LOI value of 34.0 and UL-94 V0 grade. FTIR results reflected that even without any surface modification, the level of rGO dispersion was well which resulted in reduced electrical resistance and improved properties. The TGA results indicated that the addition of IFR along with rGO into PU dramatically improves the char yields and the thermal stability of the char at high temperatures due to synergistic effect of rGO, as well as the presence of nitrogen and phosphorus in IFR system. These results were consistent with the data of dynamic FTIR. Incorporation of rGO also led to a higher storage modulus $\left(\mathrm{G}^{\prime}\right)$ and melt viscosity when compared with pure $\mathrm{PU}$ at low frequencies, which demonstrates the reinforcement effect of rGO in IFRPU composites.

Acknowledgements We are immensely grateful to Mr. Jalal Nasrollah Gavgani for supporting us financially. Besides, our special 
thanks are due to Ferdos Taleb for her kind patience to read this work and providing us with her valuable remarks.

\section{References}

1. Jung YC, Kim JH, Hayashi T, Kim YA, Endo M, Terrones M, Dresselhaus MS (2012) Macromol Rapid Commun 33:628

2. Duquesnea S, Brasa ML, Bourbigota S, Delobelb R, Caminoc G, Elingd B, Lindsayd C, Roelsd T (2001) Polym Degrad Stab 74:493

3. OECD, Direction de l'Environnement (1993) 5th Draft status report OCDE Worshop on the Risk Reduction of Brominated Flame Retardant, Neufchâ tel, Switzerland, 26 May 1992, 22-25 February 1993

4. Preliminary 1 st draft report International Programme on Chemical Safety-environmental health criteria for brominated diphenylethers, January 1993. 1st Draft report International Programme on Chemical Safety-Environmental Health Criteria for tris(2,3-dibromopropyl) phosphate and Bis(2,3-dibromopropyl) Phosphate, January 1993. United Nations Environmental Programme, PCS/EHC/92.45, non-edited reports

5. Camino G, Luda MP, Costa L (1993) In: Casal J (ed) Chemical industry and environment: general aspects-risk analysis, vol. 1. Universitat Politècnica de Catalunya, Girona, p 221

6. Duquesne S, Bras ML, Bourbigot S, Delobel R, Camino G, Eling B et al (2001) J Appl Polym Sci 82:3262

7. Wang Xin, Song Lei, Yang Hongyu, Hongdian Lu, Yuan $\mathrm{Hu}$ (2011) Ind Eng Chem Res 50:5376

8. Higginbotham AL, Lomeda JR, Morgan AB, Tour JM (2009) ACS Appl Mater Interfaces 1:2256

9. Kim KS, Zhao Y, Jang H, Lee SY, Kim JM, Kim KS, Ahn JH, Kim P, Choi JY, Hong BH (2009) Nature 457:706

10. Emtsev KV, Bostwick A, Horn K, Jobst J, Kellogg GL, Ley L, McChesney JL, Ohta T, Reshanov SA, Roehrl J, Rotenberg E, Schmid AK, Waldmann D, Weber HB, Seyller T (2009) Nat Mater 8:203

11. Song P, Yu Y, Zhang T, Fu S, Fang Z, Wu Q (2012) Ind Eng Chem Res 51:7255

12. Kshiwagi T, Du F, Douglas JF, Winey KI, Harris RH Jr, Shinlds JR (2005) Nat Mater 4:928

13. Potts JR, Murali S, Zhu YW, Zhao X, Ruoff RS (2011) Macromolecules 44:6488

14. Solar L, Nohales A, Munoz-Espi R, Lopez D, Gomez CM (2008) J Polym Sci Part B 46:1837

15. Guo YQ, Bao CL, Song L, Yuan BH, Hu Y (2011) Ind Eng Chem Res 50:7772

16. Zhu J, Morgan AB, Lamelas FJ, Wilkie CA (2001) Chem Mater 13:3774

17. Compton OC, Kim S, Pierre C, Torkelson JM, Nguyen SBT (2010) Adv Mater 22:4759

18. Wilson NR, Pandey PA, Beanland R, Rourke JP, Lupo U, Rowlands G, Romer RA (2010) New J Phys 12:125010

19. Wilson NR, Pandey PA, Beanland R, Young RJ, Kinloch IA, Gong L, Liu ZH, Suenaga K, Rourke JP, York SJ, Sloan J (2009) ACS Nano 3:2547

20. Thomas HR, Vall'es C, Young RJ, Kinloch IA, Wilson NR, Rourke JP (2013) J Mater Chem C 1:338

21. Rourke JP, Pandey PA, Moore JJ, Bates M, Kinloch IA, Young RJ, Wilson NR (2011) Angew Chem Int Ed 50:3173

22. Wang X, Hu Y, Song L, Yang H, Xing W, Lu H (2011) J Mater Chem 21:4222

23. Kim H, Miura Y, Macosko CW (2010) Chem Mater 22:3441
24. Hummers WS, Offeman RE (1958) J Am Chem Soc 80:1339

25. Stankovich S, Dikin DA, Piner RD, Kohlhaas KA, Kleinhammes A, Jia YY, Wu Y, Nguyen ST, Ruoff RS (2007) Carbon 45: 1558

26. Yousefi N, Gudarzi MM, Zheng QB, Aboutalebi SH, Sharif F, Kim JK (2012) J Mater Chem 22(25):12709

27. Aboutalebi SH, Gudarzi MM, Zheng QB, Kim JK (2011) Adv Funct Mater 21(15):2978

28. Ramanathan T, Abdala AA, Stankovich S, Dikin DA, HerreraAlonso M, Piner RD et al (2008) Nat Nanotechnol 3(6):327

29. Rafiee MA, Rafiee J, Wang Z, Song H, Yu ZZ, Koratkar N (2009) ACS Nano 3(6):3884

30. Yousefi N, Gudarzi MM, Zheng Q, Lin X, Shen X, Jia J, Sharif F, Kim JK (2013) Composites A 49:42

31. Li J, Vaisman L, Marom G, Kim JK (2007) Carbon 45(4):744

32. Li J, Kim JK, Sham ML, Marom G (2007) Compos Sci Technol 67(2):296

33. Li J, Ma PC, Sze CW, Kai TC, Tang BZ, Kim JK (2007) Adv Funct Mater 17(16):3207

34. Sham ML, Li J, Ma PC, Kim JK (2009) J Compos Mater 43(14): 1537

35. Ma PC, Siddiqui NA, Marom G, Kim JK (2010) Composites A 41(10): 1345

36. Ni Jianxiong, Tai Qilong, Hongdian Lu, Yuan Hu, Song Lei (2010) Polym Adv Technol 21:392

37. Wu Q, Wu Z, Tian H, Zhang Y, Cai S (2008) Ind Eng Chem Res 47:9896

38. Luda MP, Nada P, Costa L, Bracco P, Levchik SV (2004) Polym Degrad Stab 86:33

39. Ravey M, Pearce EM (1997) J Appl Polym Sci 63:47

40. Chen M, Shao ZB, Wang XL, Chen L, Wang ZL (2012) Ind Eng Chem Res 51(29):9769

41. Thirumal M, Khastgir D, Nando GB, Naik YP, Singha NK (2010) Polym Degrad Stab 95:1138

42. Potts JR, Lee SH, Alam TM, An J, Stoller MD, Piner RD, Ruoff RS (2011) Carbon 49:2615

43. Kim H, Abdala AA, Macosko CW (2010) Macromolecules 43:6515

44. Cao Y, Feng J, Wu P (2010) Carbon 48:3834

45. Koerner H, Price G, Pearce NA, Alexander M, Vaia RA (2004) Nat Mater 3:115

46. Yang LQ, Setyowati K, Li A, Gong SQ, Chen J (2008) Adv Mater 20:2271

47. Liang JJ, Huang Y, Zhang L, Wang Y, Ma YF, Guo TY, Chen YS (2009) Adv Funct Mater 19:2297

48. Grassie N, Zulfiqar M (1978) In: Scott (ed) Developments in polymer stabilisation, vol 1: the effect of the fire retardant ammonium polyphosphate on the thermal degradation of polyurethane. Applied Science Publisher, London, p 197

49. Bourbigot S, Le Bras M, Delobel R, Tremillon JM (1996) J Chem Soc Faraday Trans 92:3435

50. Cheng XE, Liu SY, Shi WF (2009) Prog Org Coat 65:1

51. Raghu AV, Lee YR, Jeong HM, Shin CM (2008) Macromol Chem Phys 209:2487

52. Chen TK, Tien YI, Wei KH (2000) Polymer 41:1345

53. Tien HW, Huang YL, Yang SY, Hsiao ST, Wang JY, Ma CCM (2011) J Mater Chem 21:14876

54. Thostenson ET, Chou T-W (2002) J Phys D 35:77

55. Dai JF, Li B (2010) J Appl Polym Sci 116:2157

56. Wu C, Huang X, Wang G, Wu X, Yang K, Li S, Jiang P (2012) J Mater Chem 22:7010

57. Somomon MJ, Almusallam AS, Seefeldt KF, Somwangthanaroj A, Varadan P (2001) Macromolecules 34:1864 
58. Drummy LF, Wang YC, Schoenmakers R, May K, Jackson M, Koerner H, Farmer BL, Mauryama B, Vaia RA (2008) Macromolecules 41:2135

59. Vermant J, Ceccia S, Dolgovskij MK, Maffettone PL, Macosko CW (2007) J Rheol 51:429
60. Zosel A (1982) Rheol Acta 21:72

61. Ren J, Silva AS, Krishnamoorti R (2000) Macromolecules 33:3739

62. Shante VKS, Kirkpatrick S (1971) Adv Phys 20:325

63. Chen WY, Wang YZ, Chang FC (2004) J Polym Res 11:109 